\title{
Endothelial dysfunction in COVID-19 calls for immediate attention: the emerging roles of the endothelium in inflammation caused by SARS-CoV-2
}

\author{
Weijian Hang ${ }^{1}$, Chen Chen $^{1}$, Xin A. Zhang ${ }^{2}$, Dao Wen Wang $(\bowtie)^{1}$ \\ ${ }^{I}$ Division of Cardiology, Department of Internal Medicine, and Hubei Key Laboratory of Genetics and Molecular Mechanisms of \\ Cardiological Disorders, Tongji Hospital, Tongji Medical College, Huazhong University of Science and Technology, Wuhan 430030, China; \\ ${ }^{2}$ Department of Physiology, University of Oklahoma Health Sciences Center, Oklahoma City, OK 73104, USA \\ (C) Higher Education Press 2021
}

\begin{abstract}
The COVID-19 pandemic has caused numerous deaths around the world. A growing body of evidence points to the important role of overwhelming inflammatory responses in the pathogenesis of COVID-19 and the effectiveness of anti-inflammation therapy against COVID-19 is emerging. In addition to affecting the lungs, COVID-19 can be a severe systemic inflammatory disease that is related to endothelial dysfunction. We are calling for closer attention to endothelial dysfunction in COVID-19 not only for fully revealing the pathogenic mechanism of COVID-19 but also for properly adjusting the strategy of clinical intervention.
\end{abstract}

Keywords COVID-19; endothelial dysfunction; inflammation reaction; cytokine storm

\section{Introduction}

COVID-19 has now become a severe pandemic and caused over 2243638 deaths worldwide as of February 2, 2021. Although the majority of patients with COVID-19 show mild to moderate symptoms, approximately $15 \%$ of patients progress to critical illness clinically [1]. For most physicians, the prominent characteristic of severe COVID-19 cases is severe pneumonia and respiratory dysfunction that ultimately leading to the death of the patients. However, emerging pieces of evidence suggest that overwhelmed and uncontrollable inflammatory responses that are partially attributable to virus-triggered immune response have become the determining factor in the horrible clinical development of COVID-19 [2].

SARS-CoV-2, which is the pathogen of COVID-19, is a coronavirus. A total of 38 species of coronavirus exist, among which only 7 species, including SARS-CoV and MERS-CoV that have both caused global public health emergencies, infect human beings. Angiotensin converting enzyme 2 (ACE2) has been proven to act as the receptor of

Received July 15, 2020; accepted October 14, 2020

Correspondence: Dao Wen Wang, dwwang@tjh.tjmu.edu.cn
SARS-CoV and SARS-CoV-2 by interacting with spike proteins (S proteins), the key for viruses to enter cells [3]. Notably, compared with that of SARS-CoV, the S protein of SARS-CoV-2 possesses higher ACE2 affinity; this difference may partially account for extremely high infectious capability of SARS-CoV-2 [3].

Interestingly, recent single cell sequencing (scSeq) data suggest that the high expression level of ACE2 in pericytes may cause endothelial dysfunction during SARS-CoV-2 virus infection [4]. After the 2003 SARS pandemic, several reports revealed that the SARS coronavirus can enter the endothelium and induce endothelial inflammatory response to contain viral spread [5]. Hence, the relationship between endothelial function and inflammatory response in the situation of the COVID-19 pandemic can be reasonably considered. Evidence showing that COVID19 is related to massive endothelial dysfunction [6] and flooding inflammation [7] is accumulating.

\section{Clinical evidence of endothelial injury}

As indicated by scSeq data, organs with high ACE2 expression, such as the lungs, heart, kidneys, and liver, are predicted to be susceptible to SARS-CoV-2 infection. Indeed, patients with COVID-19 have already been 
reported to develop fulminant myocarditis, hepatitis, and kidney injury [8]. Excellent reviews on the extrapulmonary manifestations of COVID-19 are available elsewhere [7]. The pathological findings in autopsy cases of patients with COVID-19 emphasized lung injury, which ranges from severe lung blood vessel congestion, monocyte and lymphocyte infiltration, focal hemorrhage, and interstitial fibrosis [9]. Focal hemorrhage underlines damaged endothelial barrier function and severe vascular leakage, which indicates the involvement of endothelial dysfunction. Recently, Varga et al. also discovered the presence of viral particles in the endothelium via electron microscopy, providing direct pathological evidence for the involvement of endothelial dysfunction in COVID-19 [10]. Once the endothelium is damaged, coagulation is initiated due to the coagulation cascade. Han et al. reported that the coagulation function of patients with COVID-19 is significantly disturbed compared with that of healthy controls [11]. A single-center, cross-sectional study also revealed that endotheliopathy and abnormal coagulation function are related to critical COVID-19 illness and death [12]. Deranged coagulation function also indicates endothelial impairment. A recent single-center, cross-sectional study demonstrated that the markers of endothelial injury, including thrombomodulin, soluble P-selectin, and CD40L, in patients with COVID-19 in the ICU are significantly elevated compared with those in non-ICU patients [12]. This is the first study to the authors' knowledge to give strong evidence that COVID-19 can be considered as an endotheliopathy.

In addition to clinical evidence, experimental evidence for coronavirus-related endothelial dysfunction has been obtained from the mouse model of murine hepatitis virus (MHV), a well-established experimental model of coronaviruses. After MHV infection, the expression of interleukin-6 (IL-6) is upregulated by 16-fold in the hepatic endothelium [13]. IL-6 is an important proinflammatory cytokine that is predominantly elevated in patients with severe COVID-19 [1]. Hence endothelial dysfunction, at least partially, possibly participates in inflammatory response in COVID-19. In addition, endothelial dysfunction may be a common phenomenon in viral infection given that in fulminant myocarditis caused by parvovirus B19, the microvascular architecture undergoes extensive angiogenesis; this phenomenon results in the formation of tiny holes on the endothelium via corrosion casting [14]. Newly formed vasculature in angiogenesis may provide an additional avenue for viruses to invade into tissues.

\section{Endothelial dysfunction and inflammatory response}

Patients with severe COVID-19 have considerably higher levels of inflammatory cytokines than patients with non- severe COVID-19 or noninfected healthy people [2]. COVID-19-caused death has become, at least partially, accepted to be the consequence of cytokine storms given that a large amount of cytokines, including TNF- $\alpha$, IL-1, and IL-6, are upregulated in patients with severe COVID19 [2]. Although the exact cause(s) of cytokine storms have yet to be unrevealed, cytokine storms aggravate the clinical situation of the patients. Some clinical trials are now investigating the possibility of using cytokine or cytokine receptor antagonists, such as tocilizumab, an IL6R antagonist, to treat severe COVID-19 [15]. The endothelium senses viral invasion through TLRs and activates IL-6 expression, which further damages endothelial function and helps viral spread [16]. This phenomenon indicates that the endothelium is also an important source of IL-6.

In addition to IL-6, upregulated cytokines and chemokines further promote the expression of adhesion molecules and draw lymphocytes for infiltration into tissue by ameboidism, which is observed in the pathological analysis of the lungs, hearts, livers, and kidneys of patients with COVID-19. However, lymphopenia is another characteristic of COVID-19 [1] that worsens the situation given that a reduced number of antiviral effectors, and even remaining lymphocytes, behave abnormally due to cytokine storms and are incapable of migrating to target sites [17]. Viral infection also induces NO expression by endothelial eNOS or iNOS. Whether NO is involved in SARS-CoV-2 infection remains to be confirmed.

The integrity of the endothelium is vital to preventing viral spread. However, molecules, such as VE-cadherin, which forms the endothelial tight cell junction, are dysregulated by cytokine storms, and this effect supports the infiltration of lymphocytes, as well as viruses, through the endothelium into tissues. Meanwhile, SARS-CoV-2 may directly invade into the endothelium and cause endothelial death, which thereby augments endothelial permeability and initiates aberrant reactions to prevent leukocyte recruitment and extravasations. Viral infection can also promote angiogenesis [14]. The involvement of angiogenesis in SARS-CoV-2 infection has yet to be confirmed.

The receptor for advanced glycation end products (RAGE) has been recently reported to be transactivated in angiotensin II (AngII)-induced endothelial inflammation [18]. ACE2 is considered as the major receptor of SARSCoV-2 and is capable of degrading AngII into Ang1-7. Hence, RAGE may be relevant to the disruption of the AngII/ACE2 pathway. In fact, a recent study that analyzed the peripheral blood mononuclear cells (PBMCs) of patients with COVID-19 revealed that the ligand of RAGE, S100A2, is significantly upregulated in the PBMCs of patients [19]. RAGE is highly abundant in type-I alveolar epithelial cells in the lung [20], partially indicating that RAGE may also participate in the 
inflammatory response in COVID-19.

Hence, as illustrated in Fig. 1, the endothelium is not only deteriorated by virus-induced inflammatory response, but also mediates cytokine response.

\section{COVID-19 treatment by endothelial protection?}

No standard or optimal treatment for COVID-19 exists. Most of the treatments for viral infections are symptomatic treatments. Recently, Monteil et al. reported that soluble
ACE2 recombinant protein can inhibit SARS-CoV-2 in vascular or renal organoids [21]. They highlighted the importance of vascular function in SARS-CoV-2 infection and indicated that recombinant ACE2 protein may be a competitor for endothelial ACE2, hence reducing viral entry into the endothelium.

Another strategy in designing regimens or developing drugs is to perturb SARS-CoV-2 landing onto and invasion into the endothelium. Arbidol, an antivirus-membrane fusion drug, is widely used in the clinical treatment of COVID-19 [22]. Several small natural molecules may also inhibit the attachment of SARS-CoV-2 onto host cells [23].

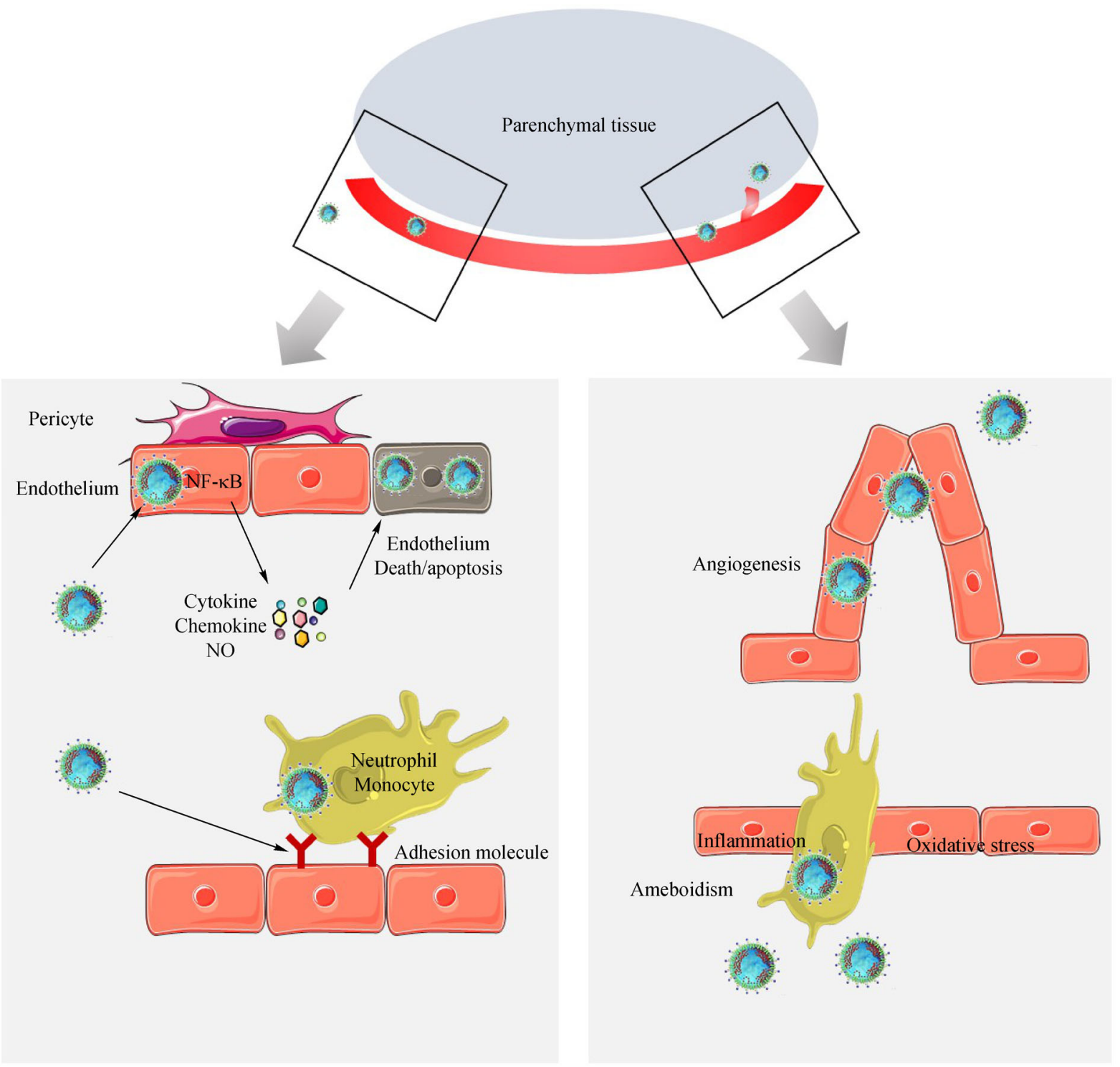

Fig. 1 Possible mechanisms of endothelial dysfunction in SARS-CoV-2 infection. The endothelium is the barrier between vascular and parenchymal tissues under the condition of viremia (upper image). However, the virus can directly invade the endothelium and promote endothelial apoptosis or death, which leads to the disruption of endothelial integrity. The endothelium itself can also secrete cytokine/ chemokine/gas molecules, as well as adhesion molecules, to attract lymphocytes (lower left). Angiogenesis may provide new pathways for further viral invasion, and lymphocytes can also infiltrate tissues through the endothelium to kill the virus inside (lower right). 
Furthermore, convalescent plasma treatment, which provides patients with passive immunity and may neutralize viral particles, is also now used in clinical practice [24].

The investigation of other viral infection models shows that the vascular endothelium is important to antiviral effect. Optimized steroid treatment can help preserve endothelial function and reduce viral titer. In fact, although still in debate, in those severe type of COVID-19 patients, short-term steroid treatment is an alternative choice. A clinical trial on the effectiveness of glucocorticoid therapy with severe COVID-19 is ongoing [25]. Recently, the clinical trial RECOVERY, which aims to test the effect of dexamethasone in hospitalized patients with COVID-19, revealed that $6 \mathrm{mg}$ of dexamethasone can reduce 28-day mortality rate among patients receiving respiratory support [26]. However, considering the side effects of dexamethasone, concluding that widely and routinely applying dexamethasone in the treatment of COVID-19 is a wise choice is premature [27].

As the barrier between virus and tissue, the endothelium is vital for the recognition of viral infection and the prevention of viral spread. Virus-induced endothelial dysfunction is strongly correlated with inflammatory response, which also supports the application of antiinflammation drugs. Antioxidant drugs, such as vitamin C, have also been applied in the treatments because oxidative stress is tightly related to inflammatory response. However, the real effectiveness of this approach still calls for clinical trials.

Endothelial dysfunction can lead to coagulation disturbance. Yin et al. reported recently that patients with severe COVID-19 can benefit from anticoagulant treatment via low-molecule-weight heparin administration [28]. Adjusting coagulation function may provide further protection to endothelial function, hence alleviating the symptoms of patients. Several endothelium-protecting drugs, including dipyridamole, have been indicated to have the potential to treat COVID-19 [29].

\section{Hurdles in the research on SARS-CoV-2- induced endothelial dysfunction}

Although endothelial dysfunction is likely contributing to COVID-19 pathogenesis, the difficulty in establishing the direct relationship between endothelial dysfunction and COVID-19 pathogenesis is discouraging. Several factors account for this uncertainty.

First, tests for the evaluation of endothelial function in clinical practice are limited, and coagulation function can only partially reflect endothelial function. New evidence suggests that thrombomodulin can be a potential endothelial marker for predicting the prognosis of patients with COVID-19; however, this marker still needs further validation in a multicenter study [12]. Knowledge of
SARS-CoV-2, although accumulating, remains limited given that SARS-CoV-2 is a new virus. Animal models for SARS-CoV-2 are still undergoing optimization. Lu et al. recently reported SARS-CoV-2 infection models of nonhuman primates; these models may accelerate the investigation of the pathogenesis of this virus and tests for vaccines or drugs [30]. Although the structural basis of ACE2 and virus spike protein has been revealed [3], the whole life process of the virus after invading the endothelium and finally inducing endothelial apoptosis or death remains confusing. The endothelium has been reported to secrete IL-6 [31]. However, the direct trigger of cytokine storms remains to be clarified. Organoid and optimized animal models may provide additional information regarding endothelial dysfunction and cytokine storms in the future.

\section{Conclusions}

Inflammatory responses and cytokine storms are now recognized as important players in the pathogenesis of COVID-19 and are related to endothelial dysfunction during infection. The high expression of ACE2 in the endothelium may provide a basis for SARS-CoV-2induced endothelial dysfunction. The capability of responding to viral invasion and secreting cytokines or chemokines reinforces the possible role of the endothelium in the development of cytokine storms. Once damaged, the disturbed integrity of the endothelium may provide an avenue for the virus to invade parenchymal tissues and cause the complications of these organs. Endothelial dysfunction also results in vascular leakage and aberrant coagulation, which ultimately lead to tissue edema and hemorrhage and can be observed in pathological analysis.

However, the mechanism(s) responsible for endothelial dysfunction has not been fully revealed. With the progress of autopsy research and the accumulation of biosamples of patients with COVID-19, additional attention should be paid to the morphological and functional changes of the endothelium through which supplementary mechanistic insight into COVID-19 pathogenesis will be gained. Drugs targeting the maintenance and preservation of endothelial and coagulation functions can also be considered for introduction into comprehensive treatments. With the development of suitable animal models, the role of endothelial dysfunction in the pathogenesis of COVID19 can be further elegantly demonstrated.

\section{Acknowledgements}

We thank all our colleagues from the Division of Cardiology, Tongji Hospital, as well as all the medical staff fighting against COVID-19, for their tremendous efforts. This work was supported by grants from the National Natural Science Foundation of China (Nos. 91839302 , 
81630010, and 81790624) and Tongji Hospital Clinical Research Flagship Program (No. 2019CR207). No funding bodies had any role in study design, data collection and analysis, decision to publish, or preparation of the manuscript.

\section{Compliance with ethics guidelines}

Weijian Hang, Chen Chen, Xin A. Zhang, and Dao Wen Wang declare that they have no competing interests. This manuscript does not involve a research protocol requiring approval by the relevant institutional review board or ethics committee.

\section{References}

1. Huang C, Wang Y, Li X, Ren L, Zhao J, Hu Y, Zhang L, Fan G, Xu J, Gu X, Cheng Z, Yu T, Xia J, Wei Y, Wu W, Xie X, Yin W, Li H, Liu M, Xiao Y, Gao H, Guo L, Xie J, Wang G, Jiang R, Gao Z, Jin Q, Wang J, Cao B. Clinical features of patients infected with 2019 novel coronavirus in Wuhan, China. Lancet 2020; 395(10223): 497 506

2. Chen G, Wu D, Guo W, Cao Y, Huang D, Wang H, Wang T, Zhang X, Chen H, Yu H, Zhang X, Zhang M, Wu S, Song J, Chen T, Han M, Li S, Luo X, Zhao J, Ning Q. Clinical and immunological features of severe and moderate coronavirus disease 2019. J Clin Invest 2020; 130(5): 2620-2629

3. Yan R, Zhang Y, Li Y, Xia L, Guo Y, Zhou Q. Structural basis for the recognition of SARS-CoV-2 by full-length human ACE2. Science 2020; 367(6485): 1444-1448

4. Chen L, Li X, Chen M, Feng Y, Xiong C. The ACE2 expression in human heart indicates new potential mechanism of heart injury among patients infected with SARS-CoV-2. Cardiovasc Res 2020; 116(6): 1097-1100

5. Huang IC, Bailey CC, Weyer JL, Radoshitzky SR, Becker MM, Chiang JJ, Brass AL, Ahmed AA, Chi X, Dong L, Longobardi LE, Boltz D, Kuhn JH, Elledge SJ, Bavari S, Denison MR, Choe H, Farzan M. Distinct patterns of IFITM-mediated restriction of filoviruses, SARS coronavirus, and influenza A virus. PLoS Pathog 2011; 7(1): e1001258

6. Teuwen LA, Geldhof V, Pasut A, Carmeliet P. COVID-19: the vasculature unleashed. Nat Rev Immunol 2020; 20(7): 389-391

7. Gupta A, Madhavan MV, Sehgal K, Nair N, Mahajan S, Sehrawat TS, Bikdeli B, Ahluwalia N, Ausiello JC, Wan EY, Freedberg DE, Kirtane AJ, Parikh SA, Maurer MS, Nordvig AS, Accili D, Bathon JM, Mohan S, Bauer KA, Leon MB, Krumholz HM, Uriel N, Mehra MR, Elkind MSV, Stone GW, Schwartz A, Ho DD, Bilezikian JP, Landry DW. Extrapulmonary manifestations of COVID-19. Nat Med 2020; 26(7): 1017-1032

8. Yang X, Yu Y, Xu J, Shu H, Xia J, Liu H, Wu Y, Zhang L, Yu Z, Fang M, Yu T, Wang Y, Pan S, Zou X, Yuan S, Shang Y. Clinical course and outcomes of critically ill patients with SARS-CoV-2 pneumonia in Wuhan, China: a single-centered, retrospective, observational study. Lancet Respir Med 2020; 8(5): 475-481

9. Yao XH, Li TY, He ZC, Ping YF, Liu HW, Yu SC, Mou HM, Wang LH, Zhang HR, Fu WJ, Luo T, Liu F, Guo QN, Chen C, Xiao HL, Guo HT, Lin S, Xiang DF, Shi Y, Pan GQ, Li QR, Huang X, Cui Y, Liu XZ, Tang W, Pan PF, Huang XQ, Ding YQ, Bian XW. A pathological report of three COVID-19 cases by minimally invasive autopsies. Chin J Pathol (Zhonghua Bing Li Xue Za Zhi) 2020; 49: 411-417 (in Chinese)

10. Varga Z, Flammer AJ, Steiger P, Haberecker M, Andermatt R, Zinkernagel AS, Mehra MR, Schuepbach RA, Ruschitzka F, Moch $\mathrm{H}$. Endothelial cell infection and endotheliitis in COVID-19. Lancet 2020; 395(10234): 1417-1418

11. Han H, Yang L, Liu R, Liu F, Wu KL, Li J, Liu XH, Zhu CL. Prominent changes in blood coagulation of patients with SARSCoV-2 infection. Clin Chem Lab Med 2020; 58(7): 1116-1120

12. Goshua G, Pine AB, Meizlish ML, Chang CH, Zhang H, Bahel P, Baluha A, Bar N, Bona RD, Burns AJ, Dela Cruz CS, Dumont A, Halene S, Hwa J, Koff J, Menninger H, Neparidze N, Price C, Siner JM, Tormey C, Rinder HM, Chun HJ, Lee AI. Endotheliopathy in COVID-19-associated coagulopathy: evidence from a single-centre, cross-sectional study. Lancet Haematol 2020; 7(8): e575-e582

13. Joseph J, Grun JL, Lublin FD, Knobler RL. Interleukin-6 induction in vitro in mouse brain endothelial cells and astrocytes by exposure to mouse hepatitis virus (MHV-4, JHM). J Neuroimmunol 1993; 42 (1): $47-52$

14. Ackermann M, Wagner WL, Rellecke P, Akhyari P, Boeken U, Reinecke P. Parvovirus B19-induced angiogenesis in fulminant myocarditis. Eur Heart J 2020; 41(12): 1309

15. Michot JM, Albiges L, Chaput N, Saada V, Pommeret F, Griscelli F, Balleyguier C, Besse B, Marabelle A, Netzer F, Merad M, Robert C, Barlesi F, Gachot B, Stoclin A. Tocilizumab, an anti-IL-6 receptor antibody, to treat COVID-19-related respiratory failure: a case report. Ann Oncol 2020; 31(7): 961-964

16. Bhargavan B, Kanmogne GD. Toll-like receptor-3 mediates HIV-1induced interleukin- 6 expression in the human brain endothelium via TAK1 and JNK pathways: implications for viral neuropathogenesis. Mol Neurobiol 2018; 55(7): 5976-5992

17. Zheng M, Gao Y, Wang G, Song G, Liu S, Sun D, Xu Y, Tian Z. Functional exhaustion of antiviral lymphocytes in COVID-19 patients. Cell Mol Immunol 2020; 17(5): 533-535

18. Pickering RJ, Tikellis C, Rosado CJ, Tsorotes D, Dimitropoulos A, Smith M, Huet O, Seeber RM, Abhayawardana R, Johnstone EK, Golledge J, Wang Y, Jandeleit-Dahm KA, Cooper ME, Pfleger KD, Thomas MC. Transactivation of RAGE mediates angiotensininduced inflammation and atherogenesis. J Clin Invest 2019; 129 (1): 406-421

19. Arunachalam PS, Wimmers F, Mok CKP, Perera RAPM, Scott M, Hagan T, Sigal N, Feng Y, Bristow L, Tak-Yin Tsang O, Wagh D, Coller J, Pellegrini KL, Kazmin D, Alaaeddine G, Leung WS, Chan JMC, Chik TSH, Choi CYC, Huerta C, Paine McCullough M, Lv H, Anderson E, Edupuganti S, Upadhyay AA, Bosinger SE, Maecker HT, Khatri P, Rouphael N, Peiris M, Pulendran B. Systems biological assessment of immunity to mild versus severe COVID-19 infection in humans. Science 2020; 369(6508): 1210-1220

20. Oczypok EA, Perkins TN, Oury TD. All the "RAGE" in lung disease: the receptor for advanced glycation endproducts (RAGE) is a major mediator of pulmonary inflammatory responses. Paediatr Respir Rev 2017; 23: 40-49

21. Monteil V, Kwon H, Prado P, Hagelkrüys A, Wimmer RA, Stahl M, Leopoldi A, Garreta E, Hurtado Del Pozo C, Prosper F, Romero JP, Wirnsberger G, Zhang H, Slutsky AS, Conder R, Montserrat N, Mirazimi A, Penninger JM. Inhibition of SARS-CoV-2 infections in engineered human tissues using clinical-grade soluble human 
ACE2. Cell 2020; 181(4): 905-913.e7

22. Deng L, Li C, Zeng Q, Liu X, Li X, Zhang H, Hong Z, Xia J. Arbidol combined with LPV/r versus LPV/r alone against corona virus disease 2019: a retrospective cohort study. J Infect 2020; 81 (1): e1-e5

23. Baglivo M, Baronio M, Natalini G, Beccari T, Chiurazzi P, Fulcheri E, Petralia PP, Michelini S, Fiorentini G, Miggiano GA, Morresi A, Tonini G, Bertelli M. Natural small molecules as inhibitors of coronavirus lipid-dependent attachment to host cells: a possible strategy for reducing SARS-COV-2 infectivity? Acta Biomed 2020; 91(1): 161-164

24. Zhang B, Liu S, Tan T, Huang W, Dong Y, Chen L, Chen Q, Zhang L, Zhong Q, Zhang X, Zou Y, Zhang S. Treatment with convalescent plasma for critically ill patients with severe acute respiratory syndrome coronavirus 2 infection. Chest 2020; 158(1): e9-e13:

25. Qin YY, Zhou YH, Lu YQ, Sun F, Yang S, Harypursat V, Chen YK. Effectiveness of glucocorticoid therapy in patients with severe coronavirus disease 2019. Chin Med J (Engl) 2020; 133(9): 10801086

26. RECOVERY Collaborative Group, Horby P, Lim WS, Emberson JR, Mafham M, Bell JL, Linsell L, Staplin N, Brightling C, Ustianowski A, ElmahiE, Prudon B, GreenC, Felton T, Chadwick D, Rege K, Fegan C, Chappell LC, Faust SN, Jaki T, Jeffery K, Montgomery A, Rowan K, Juszczak E, Baillie JK, Haynes R,
Landray MJ. Dexamethasone in hospitalized patients with covid19-preliminary report. N Engl J Med 2020; [Epub ahead of print] doi: 10.1056/NEJMoa2021436

27. Theoharides TC, Conti P. Dexamethasone for COVID-19? Not so fast. J Biol Regul Homeost Agents 2020; 34(3): 1241-1243

28. Yin S, Huang M, Li D, Tang N. Difference of coagulation features between severe pneumonia induced by SARS-CoV2 and nonSARS-CoV2. J Thromb Thrombolysis 2020; [Epub ahead of print] doi:10.1007/s11239-020-02105-8

29. Liu X, Li Z, Liu S, Sun J, Chen Z, Jiang M, Zhang Q, Wei Y, Wang X, Huang YY, Shi Y, Xu Y, Xian H, Bai F, Ou C, Xiong B, Lew AM, Cui J, Fang R, Huang H, Zhao J, Hong X, Zhang Y, Zhou F, Luo HB. Potential therapeutic effects of dipyridamole in the severely ill patients with COVID-19. Acta Pharm Sin B 2020; 10(7): 1205-1215

30. Lu S, Zhao Y, Yu W, Yang Y, Gao J, Wang J, Kuang D, Yang M, Yang J, Ma C, Xu J, Qian X, Li H, Zhao S, Li J, Wang H, Long H, Zhou J, Luo F, Ding K, Wu D, Zhang Y, Dong Y, Liu Y, Zheng Y, Lin X, Jiao L, Zheng H, Dai Q, Sun Q, Hu Y, Ke C, Liu H, Peng X. Comparison of SARS-CoV-2 infections among 3 species of nonhuman primates. bioRxiv 2020; doi:10.1101/2020.04.08.031807

31. Balaphas A, Meyer J, Perozzo R, Zeisser-Labouebe M, Berndt S, Turzi A, Fontana P, Scapozza L, Gonelle-Gispert C, Bühler LH. Platelet transforming growth factor- $\beta 1$ induces liver sinusoidal endothelial cells to secrete interleukin-6. Cells 2020; 9(5): 9 